\title{
Unusual clinical presentation of anaplastic large cell lymphoma
}

\author{
Fernando Peixoto Ferraz de Campos ${ }^{a}$, Maria Claudia Nogueira Zerbini ${ }^{b}$, \\ Aloisio Felipe-Silvac ${ }^{c}$ Angélica Braz Simões ${ }^{c}$, Silvana Maria Lovisoloc, \\ Leonardo Gomes da Fonsecad, Lorena Laborda ${ }^{a}$
}

Campos FPF, Zerbini MCN, Felipe-Silva A, et al. Unusual clinical presentation of anaplastic large cell lymphoma. Autopsy Case Rep [Internet]. 2014; 4(1): 21-27. http://dx.doi.org/10.4322/acr.2014.004

\section{ABSTRACT}

Anaplastic large cell lymphoma (ALCL), a well-recognized entity, presents a varied clinical picture and epidemiological characteristics associated with the expression of the anaplastic lymphoma kinase (ALK) protein. When classic symptoms are present (weight loss, fever, and night sweats) and combine with enlarged and easily accessible peripheral lymph nodes, diagnosis is not that difficult. But when the clinical presentation is nonspecific, a tough diagnostic task is required. HIV infection is highly associated with neoplastic disordersmainly with those of hematological origin. However, ALCL is exceptionally associated with HIV infection, and the few reported cases are ALK- $\mathrm{ALCL}^{-}$. The authors report two cases of $\mathrm{ALK}^{+} \mathrm{ALCL}$ with the unusual clinical presentation: one is associated with the HIV infection and the other presents as a fever of unknown origin (FUO) without peripheral lymphadenopathy. The latter was autopsied and was characterized by nodal and extra nodal involvement. The authors call attention to the plurality of clinical presentation of this group of lymphomas, and the early indication of bone marrow examination in cases of an FUO with elevated hepatic enzymes and lactic dehydrogenase.

Keywords: Lymphoma, Large-Cell, Anaplastic; Acquired Immunodeficiency Syndrome; Fever of Unknown Origin; Autopsy.

\section{CASE 1}

A 34-year-old female patient sought the medical facility complaining of a painful and progressive-growing mass in the left groin during the preceding 2 months. Fever and diaphoresis supervened during the last month concomitantly with $5 \mathrm{~kg}$ of weight loss. Her past medical history included the diagnosis of HIV infection since the last pregnancy 4 years ago, but under medical advice discontinued anti-retroviral therapy. The physical examination revealed a well-looking patient with normal hemodynamic parameters, afebrile, with a tender mass localized in the left groin measuring

\footnotetext{
a Department of Internal Medicine - Hospital Universitário - Universidade de São Paulo, São Paulo/SP - Brazil.

${ }^{\text {b }}$ Anatomic Pathology Service - Hospital Universitário - Universidade de São Paulo, São Paulo/SP - Brazil.

c Department of Pathology - Faculdade de Medicina - Universidade de São Paulo, São Paulo/SP - Brazil.

d Clinic Oncology Department - Instituto do Câncer de São Paulo - São Paulo/SP - Brazil.
}

Copyright $\odot 2014$ Autopsy and Case Reports - This is an Open Access article distributed of terms of the Creative Commons Attribution NonCommercial License (http://creativecommons.org/licenses/by-nc/3.0/) which permits unrestricted non-commercial use, distribution, and reproduction in any medium provided article is properly cited. 

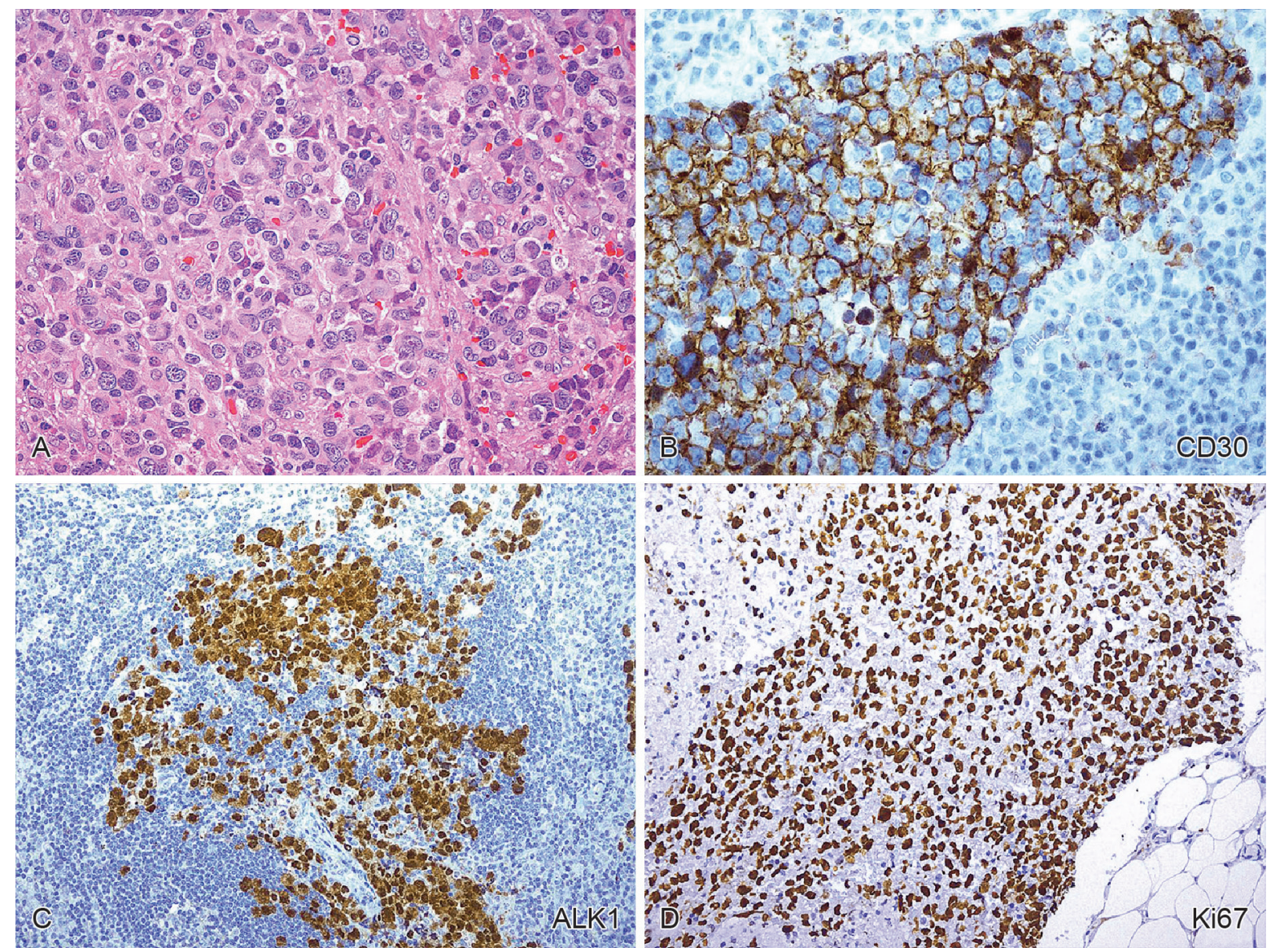

Figure 1 - Photomicrography of the lymph node. A - Presence of large, atypical, sometimes multinucleated neoplastic cells (HE, 100X); B - CD30 positive, note the lymph node sinusoidal pattern infiltration (IH, 40X); C - ALK protein positivity (IH, 10X); D - High proliferation rate showed by Ki67 (IH, 10X).

$10 \mathrm{~cm}$ at the longest axis, corresponding to adhered and hardened lymph nodes conglomerate, accompanied by unilateral left lower limb edema. Laboratory workup disclosed normal renal function, mild elevation of ALT, AST, and $\mathrm{LDH}^{\mathrm{e}}$, peripheral blood count with mild leukopenia and lymphopenia. The CRPf was slightly increased and the CD4 count was less than $50 \mathrm{cell} / \mathrm{mm}^{3}$. Ultrasound Doppler of the left groin showed enlarged lymphadenopathy, with lymph nodes measuring up to $7.9 \times 2.6 \mathrm{~cm}$ with signs of central necrosis. Deep venous thrombosis was ruled out. Abdominal computed tomography (CT) showed mesenteric, retroperitoneal lymphadenopathy, along with left external iliac artery, and left inguinal region lymphadenopathy. Thoracic and neck CT did not show significant involvement of the lymphatic chains. An inguinal lymph node was biopsied; the histological examination of which revealed a partially involved lymph node with distended sinuses by the presence of large,

\footnotetext{
e ALT = alanine aminotransferase, $A S T$ = aspartate aminotransferase, $\mathrm{LDH}=$ lactate dehydrogenase.
}

${ }^{\mathrm{f}} \mathrm{CRP}=$ C-reactive protein. atypical, cohesive neoplastic cells, sometimes with multinucleation in a horseshoe pattern ("hallmark cells"). The immunohistochemical study showed positivity for CD45, CD30 (membranous and dot pattern), CD5, and anaplastic lymphoma kinase (ALK)-1, while CD20, CD3, Epstein-Barr virus (EBV), AE1/AE3 were negative. The proliferation rate, evaluated by Ki67, was positive in $99 \%$ of the neoplastic cell population (Figure 1).

The unilateral bone marrow biopsy was normal without neoplastic infiltration. The final diagnosis was $\mathrm{ALK}^{+} \mathrm{ALCL}$ in an HIV-positive patient, with B symptoms, Ann Arbor ${ }^{g}$ stage IIXSB. The patient was referred to an oncological center for chemotherapy and restarted highly active antiretroviral therapy (HAART). She received, at first, a COP cytoreductive regimen, followed by CHOP regimen for eight cycles with complete remission. However, 12 months later, she presented a recurrence of the disease, confirmed by a cervical

g Carbone PP, Kaplan HS, Musshoff K, Smithers DW, Tubiana M. Report of the Committee on Hodgkin's Disease Staging Classification. Cancer Res. 1971;31(11):1860-1. 

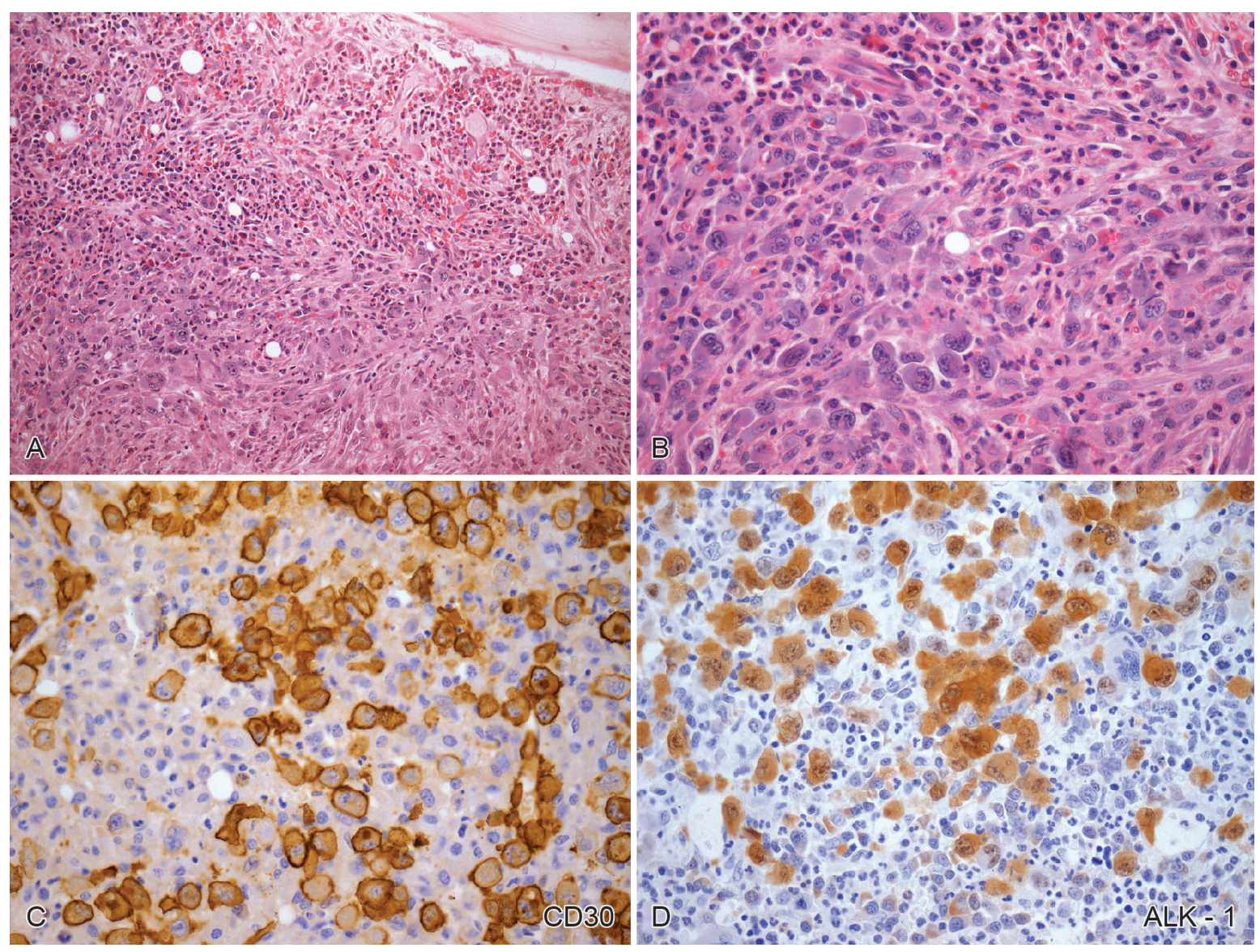

Figure 2 - Photomicrography of the bone marrow. A - (HE, 10X); and B - (HE, 100X) showing infiltration by large, atypical, neoplastic cells, with some multinucleated cells in a horseshoe pattern ("hallmark cells"); C - Immunohistochemistry positivity for CD-30 (100X); D - Immunohistochemistry positivity for ALK protein $(100 X)$.

lymph node biopsy, even though she was on HAART and the CD4 cell count was 666 cells $/ \mathrm{mm}^{3}$. At this time, the lymphadenopathy involved the cervical, supraclavicular, axillary, mesenteric, and retroperitoneal regions. Treatment was reinitiated in accordance with the lan Magrath ${ }^{\mathrm{h}}$ regimen (cyclophosphamide, methotrexate, and intrathecal cytarabine and methotrexate) for 3 cycles followed by an autologous bone marrow transplant for consolidation. During all the oncological treatment until the last followup consultation, the patient was taking HAART (lamivudine, lopinavir, ritonavir, and tenofovir). She has been free of relapse for the past 3 years.

\section{CASE 2}

A 20-year-old male patient sought the emergency unit complaining of high-grade fever and chills accompanied by malaise, headache, and weakness during the last 10 days. He referred loss of appetite and consequently $3 \mathrm{~kg}$ of weight loss (5\% of total body weight). His physical examination was normal, as well as the ophthalmoscopy. Laboratory workup showed normal renal function, glucose determination, electrolytes, hepatic enzymes, liver function tests, protein electrophoresis, and urinalysis. Serology for HIV, hepatitis B and C, toxoplasmosis, EBV, syphilis, leptospirosis, and dengue fever were negative. Rubella and cytomegalovirus serologies showed IgG positive but IgM negative. Tests for antinuclear antibody, anti-neutrophil cytoplasmic antibody, and rheumatoid factor were also negative. The tuberculin skin test was negative as well as the acid-fast bacilli research in the sputum. The thoracic CT was normal and echodoppler of the lower limbs
${ }^{\mathrm{h}}$ Magrath IT, Shad AT, Sandlund JT. Lymphoproliferative disorders in immunocompromised individuals. In: Magrath IT, editor. The non-hodgkin's lymphomas. 2nd ed. London: Oxford University Press, 1997. p. 955-74. 


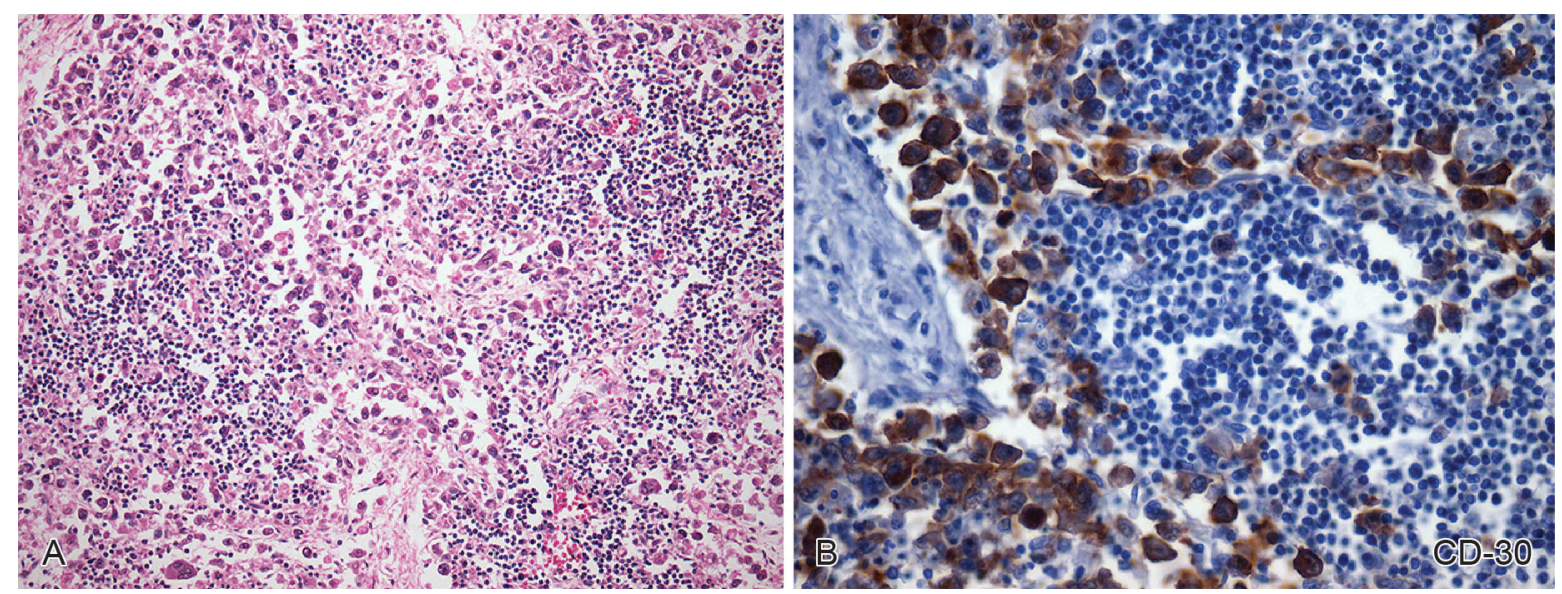

Figure 3 - Photomicrography of the lymph node. A - Effacement of the original architecture due to sinusoidal infiltration by large atypical multinucleated cells (HE, 100X); B - Immunohistochemistry positivity for CD30 (HE, 400X).

ruled out the diagnosis of deep venous thrombosis. The cerebrospinal fluid (CSF) examination was normal. Four sets of blood samples, urine, and CSF cultures were negative for bacteria, fungus, and acid-fast bacilli. The patient remained hospitalized presenting a daily temperature of $38.5^{\circ} \mathrm{C}$ and $39^{\circ} \mathrm{C}$ and was recorded as a fever of unknown origin (FUO). In this setting, he underwent a transesophageal echodopplercardiogram, which was normal. The determination of a high titer of ferritin was odd, which was interpreted as an inflammatory marker or even the possibility of Still's disease, without other diagnostic criteria. The abdominal ultrasound and CT were normal despite the progressive raising determination of liver enzymes (AST, ALT, APh and YGT) and LDH'. Nevertheless he was submitted to a wedge liver biopsy through laparoscopy, which did not detect any abnormality in the abdominal cavity. The histological examination of the liver specimen showed non-specific findings: preserved lobular architecture, with moderate neutrophilic infiltration of portal tract with histiocytes, mild biliary ductal proliferation. The hepatocytes, Kupfer cells, as well as the central veins were also preserved. Bone marrow aspiration resulted in dry tap, which was followed by a bone marrow biopsy, which showed hypoplasia of the all hematopoietic series and focal infiltration by large lymphoid cells, with nuclear pleomorphism, atypia and evident nucleoli.

The patient evolved with lower limb cellulitis and septic shock, and died before the complete diagnosticworkuphas beencompleted. Unfortunately

\footnotetext{
ALT = alanine transaminase; $\mathrm{APh}=$ alkaline phosphatase; $\mathrm{AST}=$ aspartate transaminase; $\mathrm{\gamma GT}$ = gamma glutamyl transferase; $\mathrm{LDH}=$ lactate dehydrogenase.
}

the bone marrow biopsy was not prioritized over the other examinations, being undertaken lately in the course of the disease. The diagnosis was confirmed by the immunohistochemical report, which showed a profile consistent with $\mathrm{ALK}^{+} \mathrm{ALCL}$ : (positive for CD30, ALK, and EMA, and negative for CD20, CD3, CD15, CD43, CD34, CD31, and myeloperoxidase) (Figure 2).

The autopsy revealed generalized lymphadenopathy (lymph nodes measuring up to 2 $\mathrm{cm}$ ) involving the axillary, mediastinal, abdominal, and lower limb chains, which showed sinusoidal infiltration by large, atypical multinucleated cells (Figure 3).

The lungs, liver, and spleen also showed lymphomatous infiltration (Figure 4). The final diagnosis was $\mathrm{ALK}^{+} \mathrm{ALCL}$ and the immediate cause of death was septic shock with massive bilateral pulmonary hemorrhage.

\section{DISCUSSION}

In 1985, Stein et al. ${ }^{1}$ first described ALCL and since then its definition has greatly evolved. Nowadays, this lymphoma is fairly well characterized and currently recognized by the $\mathrm{WHO}^{2,3}$ as a defined entity. ALCL is characterized by a proliferation of large lymphoid cells with distinctive morphology: hallmark cells, marked sinus and perivascular growth (angiocentrism) pattern, a strong expression of CD30, and cytotoxic granules protein, expressing (or not) the ALK protein. This lymphoma comprises approximately $3 \%$ of adult and $10-30 \%$ of childhood 


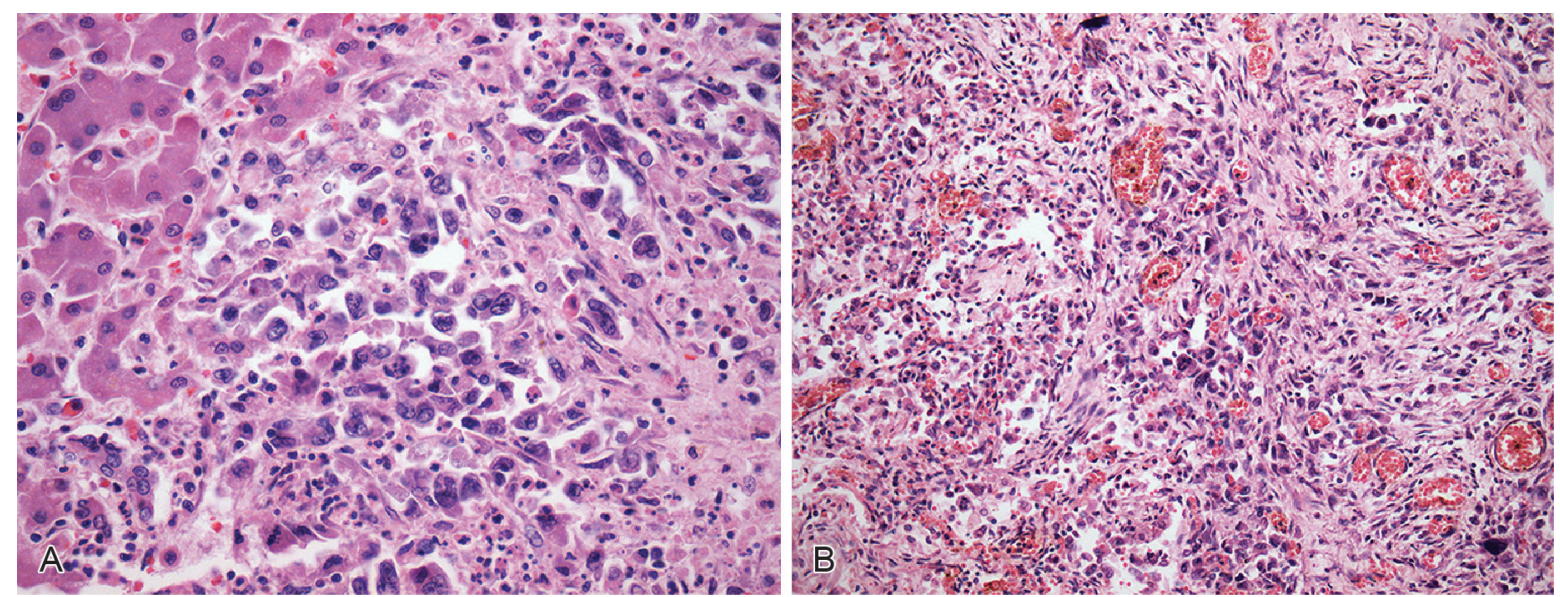

Figure 4 - A - Photomicrography of the liver showing microscopic and multifocal infiltration of the portal tract by large atypical multinucleated cells (HE, 400X); B - Photomicrography of the lung showing focal infiltration of large atypical multinucleated cells in the parenchyma and perivascular. Note hemorrhagic foci and organizing pneumonia (HE, 100X).

non-Hodgkin lymphomas (NHLs). ${ }^{4,5}$ Chromosomal translocations, such as $\mathrm{t}(2 ; 5)(\mathrm{p} 23 ; \mathrm{q} 35), \mathrm{t}(1 ; 2)(\mathrm{p} 21$; $\mathrm{q} 23), \mathrm{t}(2 ; 3)(\mathrm{p} 23 ; \mathrm{q} 21)$ and $\mathrm{t}(2 ; 17)(\mathrm{p} 23 ; \mathrm{q} 23)$, are responsible for the expression of the ALK protein, which apparently is associated with younger patients and a better prognosis.

Therefore, $A L C L$ is divided into three groups, namely: ALCL-ALK', ALCL-ALK- and cutaneous ALCL. Disregarding the cutaneous group, this lymphoma may present clinically as a localized as much as extranodal widespread disease in non-HIV-infected individuals. Unusual clinical presentation, including fever, multiple organ failure, shock, and adrenal insufficiency can be associated with subtypes of ALCL, particularly in cases of extranodal involvement. ${ }^{6,7}$ This heterogeneous clinical presentation challenges the clinician and may be responsible for a considerably delayed diagnosis.

Although it is decreasing in the era of HAART, the association of HIV infection and the development of various malignancies still remains high when compared with the general population. ${ }^{8,9}$ In this setting, B-cell NHLs are more frequently reported, unlike T-cell lymphomas, which account for $1.4 \%$ of 6,788 lymphomas in a population of 302,834 persons with AIDS. Although rare, the relative risk of T-cell lymphoma, estimated by standardized incidence ratio, was 15.0 (95\% confidence interval: 10.0-21.7)..$^{10}$ In another study, the incidence of T-cell lymphoma was $2.6 \%$ in a series of 429 AIDSrelated lymphomas. ${ }^{5}$ Among the T-cell lymphomas in the AIDS population, ALCL is even more rarely observed with the incidence ranging between $22 \%$ and $28 \% .^{5,11,12}$

Until the report of Perez et al. in 2010,13 37 cases of HIV-infected ALCL cases were identified. In the English literature in 2012, this number did not exceed 50 cases. ${ }^{8,14}$ These cases were characterized by the involvement of a young population (mean age 38 years), with male predominance ( $\mathrm{M}: \mathrm{F}=4: 1$ ), a median CD4 count of $83 \mathrm{cell} / \mathrm{mm}^{3}$, a rare expression of the ALK protein, an exclusive extranodal presentation, and a very aggressive clinical course with the median overall survival of 5 months. ${ }^{8,12,13}$ Case 1 , reported herein, calls attention to its unusual presentation: it affected a female patient; it presented as an inguinal bulky disease along with lymph node enlargement of the iliac and periaortic chains; there was no clinical or radiological evidence of extra nodal disease; there was a positive expression of the ALK protein; and a non-fatal outcome.

In a study conducted by Mosunjac et al. ${ }^{6} 5$ cases of ALCL in a series of 23 presented clinically as an FUO. In this series beyond fever, other symptoms were nonspecific and the duration ranged from 1 week to 3 months. Among the laboratory findings, attention was called to leukocytosis with neutrophilia, thrombocytopenia, and abnormal coagulation tests. Lactic acidosis, elevated hepatic enzymes, APh, and LDH were present in $80 \%$ of the cases. Only one case showed large pre- and retrosternal masses misinterpreted as scar tissue of a previous coronary bypass grafting. All five cases were autopsied and the major findings were compatible with extranodal involvement of $A L C L$, and 
$80 \%$ predominantly showed a slight enlargement of the deep-seated retroperitoneal, mediastinal, and abdominal lymph nodes. Extra nodal sites mainly characterized the involvement of the liver, lungs, spleen, bone marrow, and gut. This neoplastic infiltration was represented by gross tumor masses (predominantly in the liver and mediastinal lymph nodes) or diffuses microscopic involvement, which characterized the lung, gastrointestinal tract, bladder, kidneys, and thyroid. Hemophagocytosis was observed in the bone marrow of two cases. In this series, all but one case were ALK-.

Case 2, reported herein, showed an $\mathrm{ALK}^{+}$ ALCL in a young patient, which presented as an FUO, with a fast fatal outcome. The patient was thoroughly investigated and the diagnosis was, unfortunately, not concluded before the death. After the initial workup, the raise in LDH determination directed the investigation towards a hematological malignancy, through the bone marrow examination. The physical examination and the radiological study could not help in determining the diagnosis or lymphadenopathy, most probably because of their small size, which was further observed at the autopsy. This case is an example of a deceitful presentation form of ALCL, which means it appeared as an FUO without marked evidence of lymph node involvement. Our Case 2 presents some similar characteristics of the Mosunjac et al. ${ }^{6}$ series, but showed the presence of the ALK protein, which, in this case, did not show a favorable prognosis. In addition to the extranodal involvement, the lymph nodes were equally involved in a disseminated manner characterized by small lymph nodes, similar to that observed by Mosunjac et al. ${ }^{6}$ Extra nodal infiltration was characterized by a diffuse and microscopic pattern, concealing the clinical suspicion and challenging the imaging diagnosis. Systemic symptoms and the aggressive course of these cases of ALCL are thought to be related to increase in expression of cytokines such as G-CSF and IL-6 or IL-2. ${ }^{15}$ Janik et al. ${ }^{16}$ showed increased levels of the soluble IL-2 receptor in the serum of patients with $\mathrm{ALK}^{+} \mathrm{ALCL}$. In the series of Mosunjac et al. ${ }^{6}$ the strong membranous expression of CD25 (IL-2 receptor) confirmed Janik's observation. The cytokines' storm observed in these severe cases of ALCL are in accordance with the hemophagocytic syndrome also observed in some cases. Our Case 2 was $\mathrm{ALK}^{+} \mathrm{ALCL}$, which is associated with hypercytokinemia; therefore, the dramatic clinical course as well as the high level of ferritin may be manifestations of the release of the cytokines.

\section{CONCLUSION}

Even though ALCL is a well-defined entity, this neoplasia presents a plurality of clinical pictures, and has to be considered among HIVinfected patients and those with the diagnosis of an FUO. In the latter group of patients, we recommend early biopsy of the bone marrow if no peripheral and accessible lymph node is present, mainly in those cases where the LDH and hepatic enzymes are unexpectedly increased.

\section{REFERENCES}

1. Stein H, Mason DY, Gerdes J, et al. The expression of Hodgkin's disease associated antigen Ki-1 in reactive and neoplastic lymphoid tissue: evidence that Reed-Sternberg cells and histiocytic malignancies are derived from activated lymphoid cell. Blood. 1985;66:3681-95.

2. Mason DY, Harris NL, Delsol G, et al. Anaplastic large cell lymphoma, ALK-negative. In: Swerdlow SCE, Campo E, Harris NL, et al., editors. WHO classification of tumors of haematopoietic and lymphoid tissues. Lyon: IARC; 2008. p. 317-9.

3. Delson G, Falini B, Muller-Hermelink HL, et al. Anaplastic large cell lymphoma, ALK-positive. In: Swerdlow SCE, Campo E, Harris NL, et al., editors. WHO classification of tumors of haematopoietic and lymphoid tissues. Lyon: IARC; 2008. p. 312-6.

4. Jafe ES. Anaplastic large cell lymphoma: the shifting sands of diagnostic hematopathology. Mod Pathol. 2001;14:219-28. http://dx.doi.org/10.1038/modpathol.3880289

5. Arzoo KK, Bu X, Espina BM, Serevinatne L, Nathwani B, Levine AM. T-cell lymphoma in HIV-infected patients. J Acquir Immune Defic Syndr. 2004;36:1020-7. http://dx.doi. org/10.1097/00126334-200408150-00004

6. Mosunjac MB, Sundstrom BJ, Mosunjac MI. Unusual presentation of anaplastic large cell lymphoma with clinical course mimicking fever of unknown origin and sepsis: Autopsy study of five cases. Croat Med J. 2008;49:660-8. http://dx.doi.org/10.3325/cjm.2008.5.660

7. Campos FPF, Felipe-Silva A, Zerbini MCN. Anaplastic large cell lymphoma ALK-negative clinically mimicking alcoholic hepatitis - a review. Autopsy Case Rep [Internet]. 2013;3(3):119. http://dx.doi.org/10.4322/acr.2013.023

8. Genet P, Chaoui D, Masse V, et al. Anaplastic large cell lymphoma occurring in an HIV-positive patient. Case Rep Hematol. 2012; Article ID 180204. http://dx.doi. org/10.1155/2012/180204

9. Taniai H, Furusyo N, Murata M, et al. A case report of human immunodeficiency virus-associated anaplastic lymphoma 
kinase protein-negative anaplastic large cell lymphoma. SpringerPlus. 2013;2:400-5.

10. Biggar RJ, Engels EA, Frisch M, Goedert JJ. Risk of T-cell lymphomas in persons with AIDS. J Acquir Immune Defic Syndr. 2001;26(4):371-6. http://dx.doi.org/10.1097/00126334200104010-00015

11. Castillo J, Beltran BE, Bibas M, et al. Prognostic factors in patients with HIV-associated peripheral T-cell lymphoma: a multicenter study. Am J Hematol. 2011;86:256-61. http:// dx.doi.org/10.1002/ajh.21947

12. Castillo J, Perez K, Milani C, Dezube BJ, Pantanowitz L. Peripheral T-cell lymphomas in HIV-infected individuals: a comprehensive review. J HIV Ther. 2009;14:34-40.
13. Perez K, Castillo J, Dezube BJ, Pantanowitz L. Human immunodeficiency virus-associated anaplstic large cell lymphoma. Leuk Lymphoma. 2010;51:430-8. http://dx.doi. org/10.3109/10428190903572201

14. Kumar S, Wanchu A, Sharma A, et al. Spinal cord compression caused by anaplastic large cell lymphoma in an HIV infected individual. J Cancer Res Ther. 2010;6:376-8. http://dx.doi. org/10.4103/0973-1482.73358

15. Harada $\mathrm{Y}$, Yamada S, Murakami S, et al. Ki-1 lymphoma with nodular involvement in liver and spleen: possible role of cytokines in systemic manifestation of fever and leukocytosis. Dig Dis Sci. 2000;45:2240-6.

16. Janik JE, Morris JC, Pittaluga S, et al. Elevated serum-soluble interleukin-2 receptor levels in patients with anaplastic large cell lymphoma. Blood. 2004;104:3355-7. http://dx.doi. org/10.1182/blood-2003-11-3922

\section{Conflict of interest: None.}

Submitted on: $1^{\text {st }}$ January 2014

Accepted on: $15^{\text {th }}$ March 2014

Correspondence: Divisão de Clinica Médica Hospital Universitário da Universidade de São Paulo

Av. Prof. Lineu Prestes, 2565 - Cidade Universitária - São Paulo/SP - Brazil

CEP: 05508-000 - Phone: +55 (11) 3091-9275

E-mail: fpfcampos@gmail.com 